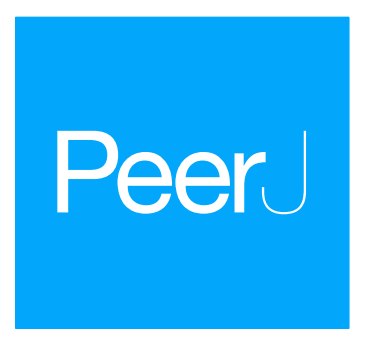

Submitted 14 February 2019

Accepted 17 July 2019

Published 12 August 2019

Corresponding author

ChunsunGu, chunsungu@cnbg.net, chunsungu@126.com

Academic editor

Xiangyang Xu

Additional Information and Declarations can be found on page 8

DOI 10.7717/peerj.7505

Copyright

2019 Wang et al.

Distributed under

Creative Commons CC-BY 4.0

OPEN ACCESS

\section{Efficient virus-induced gene silencing in Hibiscus hamabo Sieb. et Zucc. using tobacco rattle virus}

\author{
Zhiquan Wang ${ }^{1}$, Xiaoyang $\mathrm{Xu}^{1}$, Longjie $\mathrm{Ni}^{1,2}$, Jinbo $\mathrm{Guo}^{1}$ and Chunsun $\mathrm{Gu}^{1}$ \\ ${ }^{1}$ Jiangsu Key Laboratory for the Research and Utilization of Plant Resources, Institute of Botany, \\ Jiangsu Province and Chinese Academy of Sciences, Nanjing, Jiangsu, China \\ ${ }^{2}$ College of Forest Sciences, Nanjing Forestry University, Nanjing, Jiangsu, China
}

\section{ABSTRACT}

Background. Hibiscus hamabo Sieb. et Zucc. is a semi-mangrove plant used for the ecological restoration of saline-alkali land, coastal afforestation and urban landscaping. The genetic transformation $H$. hamabo is currently inefficient and laborious, restricting gene functional studies on this species. In plants, virus-induced gene silencing provides a pathway to rapidly and effectively create targeted gene knockouts for gene functional studies.

Methods. In this study, we tested the efficiency of a tobacco rattle virus vector in silencing the cloroplastos alterados 1 (CLA1) gene through agroinfiltration.

Results. The leaves of $H$. hamabo showed white streaks typical of $C L A 1$ gene silencing three weeks after agroinfiltration. In agroinfiltrated H. hamabo plants, the CLA1 expression levels in leaves with white streaks were all significantly lower than those in leaves from mock-infected and control plants.

Conclusions. The system presented here can efficiently silence genes in H. hamabo and may be a powerful tool for large-scale reverse-genetic analyses of gene functions in H. hamabo.

Subjects Molecular Biology, Plant Science

Keywords Tobacco rattle virus vector, Virus-induced gene silencing, Cloroplastos alterados 1, Gene silencing, Hibiscus hamabo Sieb. et Zucc.

\section{INTRODUCTION}

Hibiscus hamabo Sieb. et Zucc., which is a shrub plant in the genus Hibiscus, family Malvaceae, is an important semi-mangrove plant (Nakanishi, 1979). Because of its excellent salt tolerance and morphological characteristics, $H$. hamabo is widely used in public parks, waysides and coastal sands near sea level (Fowler, 2017; Li et al., 2012; Yang, Du \& Wang, 2008). In addition, $H$. hamabo is a good plant material for exploring the salt-stress response mechanisms of woody plants ( $L i$ et al., 2012). Gene manipulation technologies can be used to determine the gene functions and regulatory mechanisms in H. hamabo. However, to date, the inefficient and laborious genetic transformation procedures used have impeded such research. Additionally, transcriptome analyses have mined many excellent genes that are awaiting functional identification. Appropriate techniques need to be applied successfully to allow the study of gene functions in this plant. 
Virus-induced gene silencing (VIGS) is a powerful technology that uses engineered viruses to specifically silence host gene expression through post-transcriptional gene silencing (Becker \& Lange, 2010; Krishnan et al., 2015; Purkayastha \& Dasgupta, 2009). VIGS is an effective method for large-scale analysis of genes and their functions, and it has been successfully performed in many plants, including tobacco, Arabidopsis, tomato, cotton, wheat, and many woody plants (Burch-Smith et al., 2006; Jiang et al., 2014; Kumagai et al., 1995; Orzaez et al., 2009; Scofield et al., 2005). VIGS works via a mechanism that is similar to that of RNA interference (Baulcombe, 1999; Baulcombe, 2004; Burch-Smith et al., 2004; Lu et al., 2003; Waterhouse, Wang \& Lough, 2001). Double-stranded (ds) RNA is the key to the VIGS process; the dsRNA can be cleaved into short interfering (si) RNAs of 21 to 25 nucleotides (Burch-Smith et al., 2004; Jiang et al., 2014; Lu et al., 2003). Two strands can be obtained from the siRNAs: the guide and passenger strands. The RNA-induced silencing complex incorporates the guide strand to degrade the specific single-stranded RNA that is complementary to the guide RNA, and then, the passenger strand is degraded (Mustafa et al., 2016). As a result, the target gene is silenced and large amounts of siRNAs are produced (Fuchs, Damm-Welk \& Borkhardt, 2004).

Agrobacterium-mediated VIGS protocols based on tobacco rattle virus (TRV) have been developed and optimized in cotton, and previous studies showed that TRV is a useful vector for VIGS in Gossypium species (Gao et al., 2011; Ge et al., 2016). Tobacco rattle virus (TRV), belonging to genus Tobravirus (family Virgaviridae), is a suitable virus vector system for VIGS (Jiang et al., 2014). A positive sense single-stranded RNA genome exists in TRV, consisting of two components, RNA 1 and RNA 2 (Mustafa et al., 2016). RNA 1 encodes genes with viral replication and movement functions, while RNA 2 encodes the coat protein and some nonessential structural proteins that can be replaced by foreign sequences (Hayward, Padmanabhan \& Dinesh-Kumar, 2011). The TRV vector has been used in G. spp., Arabidopsis and Vernicia fordii to silence the cloroplastos alterados 1 (CLA1) gene, which is involved in chloroplast development (Jiang et al., 2014; Manhães, De Oliveira \& Shan, 2015; Mustafa et al., 2016). The CLA1 gene is highly conserved in various plant species (Jiang et al., 2014). The silencing phenotypes of albino leaves were observed in Vernicia fordii two weeks after inoculation using a heterologous TRV-based VIGS system, in which CLA1 was isolated from Populus tomentosa Carr. (Jiang et al., 2014). The silenced CLA1 is a useful marker for determining silencing efficiency because of the bleached phenotype (Mustafa et al., 2016).

In this study, we tested the feasibility of the TRV-VIGS system in H. hamabo using the HhCLA1 gene as a reporter. The agroinfiltrated leaves of $H$. hamabo showed white streaks typical at three weeks after infection, and the expression levels of the HhCLA1 gene in leaves with white streaks were significantly lower than those in leaves from mock-infected and control plants. Thus, the TRV-VIGS system can efficiently silence genes in H. hamabo. To our knowledge, this is the first report of the successful application of VIGS in H. hamabo. 


\begin{tabular}{|c|c|}
\hline Primer name & Primer sequence \\
\hline HhCLA1-F & CTGTGAGTAAGGTTACCGAATTCTCATGTTGTCACTGAGAAAGG \\
\hline HhCLA1-R & CTCGAGACGCGTGAGCTCCATAGCAAATCTTACAGGCAG \\
\hline$q H h C L A 1-\mathrm{F}$ & CGCCAGGGAACAAAGGGGTT \\
\hline$q H h C L A 1-\mathrm{R}$ & AATCGTGCATCCGCGACAGT \\
\hline $18 S$ rRNA-F & GGTCGGATTTGGAACGGCGA \\
\hline $18 S$ rRNA-R & CTCCACGGGCGTATCGAGG \\
\hline
\end{tabular}

Notes.

Underlines indicate restriction enzyme cleavage sites used in this TRV-VIGS system.

\section{MATERIALS \& METHODS}

\section{Plant materials and growth conditions}

Seeds of H. hamabo were collected from Nanjing's Sun Yat-Sen Memorial Botanical Garden. The seeds were then treated with concentrated sulfuric acid for $15 \mathrm{~min}$ and rinsed thoroughly with sterile water. The pretreated seeds were sown into flowerpots containing a mixture of peat and vermiculite $(1: 1, \mathrm{v}: \mathrm{v})$ in an illuminated incubator with controlled temperatures of $26^{\circ} \mathrm{C} / 22^{\circ} \mathrm{C}$ under a $16 \mathrm{~h} / 8 \mathrm{~h}$ (day/night) photoperiod.

\section{Sequence analysis}

Based on the HhCLA1 sequence (GenBank accession no. MK229167), the deduced protein sequence was analyzed with CLA1 proteins of other species using ClustalX (Liu et al., 2015). The amino acid sequences were obtained from NCBI (https://www.ncbi.nlm.nih.gov/). Then, the sequences were used to construct a phylogenetic tree, which was drawn with MEGA 7.0 using the Neighbor-Joining (NJ) method and 1,000 bootstrap replicates.

\section{VIGS vector construction}

Total RNA was extracted from the leaves of H. hamabo using a Plant RNeasy Mini Kit (Qiagen, Hilden, Germany). The first-strand cDNA was synthesized using a SuperScript II reverse transcriptase kit (TaKaRa, Dalian, China). The primer pair HhCLA1-F and HhCLA1-R (Table 1) was designed using Oligo 6.0 software (Molecular Biology Insights, Inc., Cascade, CO, USA) based on the conserved domain of HhCLA1. To amplify partial fragments of $H h C L A 1$, the primer pair, cDNA and PrimeSTAR ${ }^{\mathrm{TM}}$ HS DNA polymerase (TaKaRa) were used. EcoRI enzyme cleavage sites were added to the upstream primers and Sac I enzyme cleavage sites were added to the downstream primers. PCR product were generated with the following reaction program: 30 cycles of $98^{\circ} \mathrm{C}$ for $10 \mathrm{~s}, 60^{\circ} \mathrm{C}$ for $5 \mathrm{~s}$ and $72{ }^{\circ} \mathrm{C}$ for $1 \mathrm{~min}$. The reactions final volume was $50 \mu \mathrm{L}$, containing $25 \mu \mathrm{L}$ of $2 \times$ PrimeSTAR $^{\mathrm{TM}}$ GC Buffer, $4 \mu \mathrm{L}$ dNTP mixture $(2.5 \mathrm{mM}), 0.2 \mu \mathrm{M}$ of each primer (final), $100 \mathrm{ng}$ of cDNA and $0.5 \mu \mathrm{L}$ of PrimeSTAR ${ }^{\mathrm{TM}} \mathrm{HS}$ DNA Polymerase $(2.5 \mathrm{U} / \mu \mathrm{L})$. The pTRV1 and $p T R V 2$ vectors were used in this study as described previously (Gao et al., 2011; Liu, Schiff \& Dinesh-Kumar, 2002). The PCR products were ligated into pTRV2 (Fig. S1) (double-digested with EcoRI and Sac I enzymes) using a ClonExpress ${ }^{\circledR}$ IIOne Step Cloning Kit (Vazyme, Nanjing, China). The resulting vector was designated pTRV2-HhCLA1. 


\section{Agroinfiltration}

pTRV2-HhCLA1 was transformed into Agrobacterium tumefaciens strain 'GV3101' using the freeze-thawing method (Höfgen \& Willmitzer, 1988). PCR-confirmed single colonies were then selected and independently inoculated into three $\mathrm{mL}$ of Luria-Bertani medium containing $25 \mathrm{mg} / \mathrm{L}$ rifampicin and $50 \mathrm{mg} / \mathrm{L}$ kanamycin and grown overnight in a shaker at $28^{\circ} \mathrm{C}$. For the VIGS assay, 3-mL cultures of A. tumefaciens strain GV3101 independently containing either PTRV1 or pTRV2 was grown overnight in the same culture conditions. These overnight starter cultures were subsequently used to inoculate $50-\mathrm{mL}$ cultures that were grown overnight at $28{ }^{\circ} \mathrm{C}$. Agrobacterium cultures were harvested by centrifugation at $4,000 \times \mathrm{g}$ for $10 \mathrm{~min}$, and the pellets were resuspended in an infiltration buffer (10 mM MES (2- (4- Morpholino) Ethanesulfonic Acid), $10 \mathrm{mM} \mathrm{MgCl}_{2}$ and $200 \mu \mathrm{M}$ acetosyringone, $\mathrm{pH}$ 5.6) at an optical density of 2.0 at $600 \mathrm{~nm}$ and incubated at room temperature for $3 \mathrm{~h}$ without shaking. Agrobacterium cultures containing mixtures of pTRV1 and pTRV2-HhCLA1 (1: 1 ratio) were infiltrated with 1-mL needleless syringes into the backs of cotyledons of 2-week-old H. hamabo seedlings, following a protocol described previously (Gao et al., 2011). To determine whether the TRV vector can directly infect H. hamabo, a mixture of Agrobacterium cultures containing pTRV1 and pTRV2 constructs in a 1: 1 ratio was infiltrated into the backs of cotyledons of eight 2-week-old $H$. hamabo to serve as the mock. Experimental and non-injected control plants were transferred to a growth chamber and maintained under set conditions.

\section{Quantitative real-time PCR (qPCR)}

To determine the relative levels of the endogenous HhCLA1 transcripts in infected leaves exhibiting visible silencing phenotypes, $\mathrm{qPCR}$ was performed using the primer pair qHhCLA1-F/qHhCLA1-R (Table 1). For the experiments, leaves from plants with significant white streak symptoms were analyzed in comparison with leaves of the mock and control plants after three weeks of agroinfiltration. Four groups of plants with significant white streak symptoms, one control group, and one mock group, in order to analyze the test results more accurately, were further analyzed in this experiment. Each group contained three biological replicates. Total RNA was extracted from these leaves using a Plant RNeasy Mini Kit (Qiagen) and treated with DNase I to remove residual DNA. The first-strand cDNA was synthesized using a SuperScript II reverse transcriptase kit (TaKaRa). The qPCR assays were performed using the SYBR Green PCR Master Mix (Bimake, Houston, TX, USA) and a StepOne ${ }^{\mathrm{TM}}$ System (ABI, USA). The transcript level of $18 S$ rRNA served as the internal controls. All experiments were repeated three times. The relative gene expression level was calculated using the $2^{-\Delta \Delta \mathrm{Ct}}$ method (Gu et al., 2018; Liao et al., 2016).

\section{Statistical analysis}

One-way analysis of variance (ANOVA) and Duncan's multiple range test $(P<0.05)$ were performed using IBM SPSS (Version 21). 


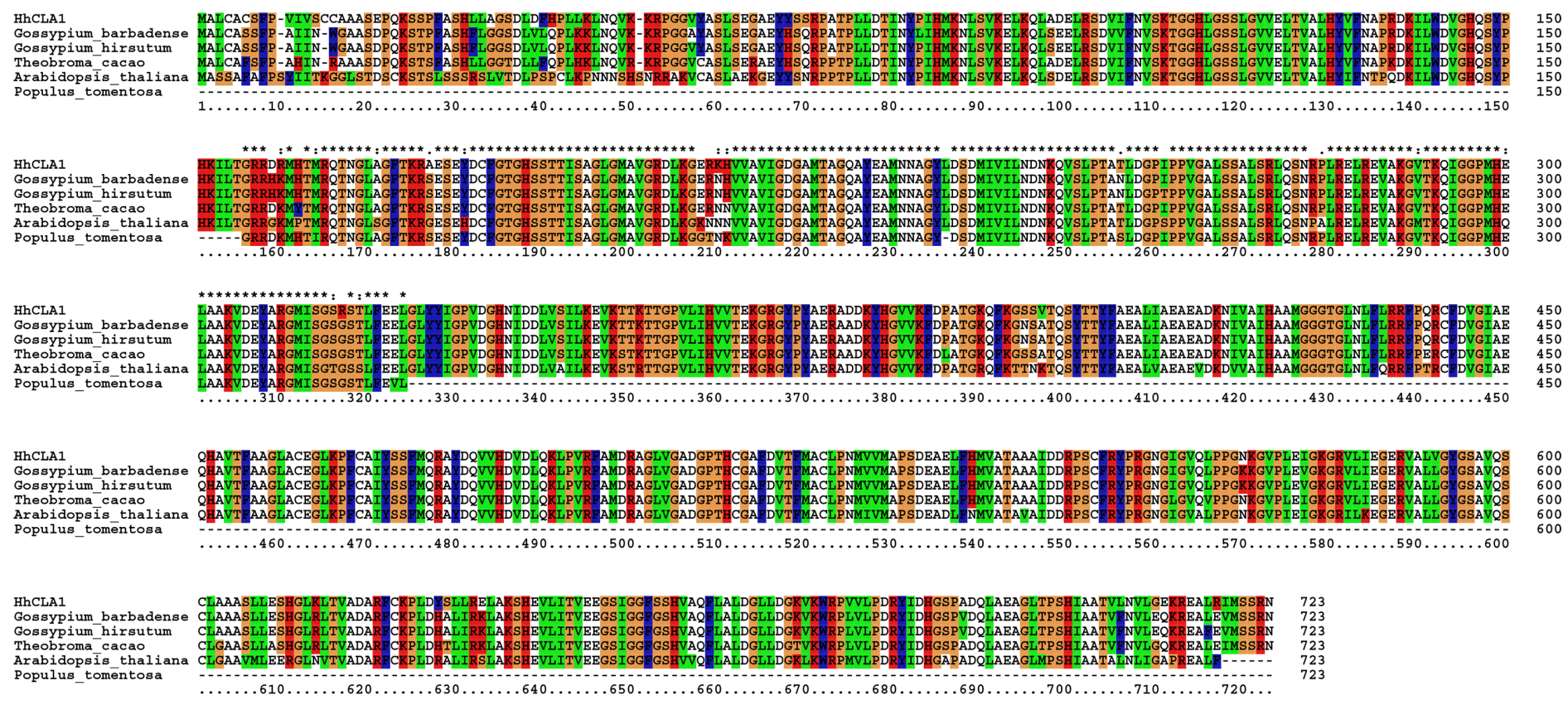

Figure 1 Multiple alignment of the HhCLA1 amino acid sequence with sequences from different species using the ClustalW program. Multiple alignment of protein sequences of the HhCLA1 gene in Hibiscus hamabo Sieb. et Zucc., Gossypium barbadense (ABN13970.1), Gossypium hirsutum NP_001314056.1), Theobroma cacao (EOY06359.1), Arabidopsis thaliana (NP_193291.1) and Populus tomentosa (AGT02336.1).

Full-size DOI: $10.7717 /$ peerj.7505/fig-1
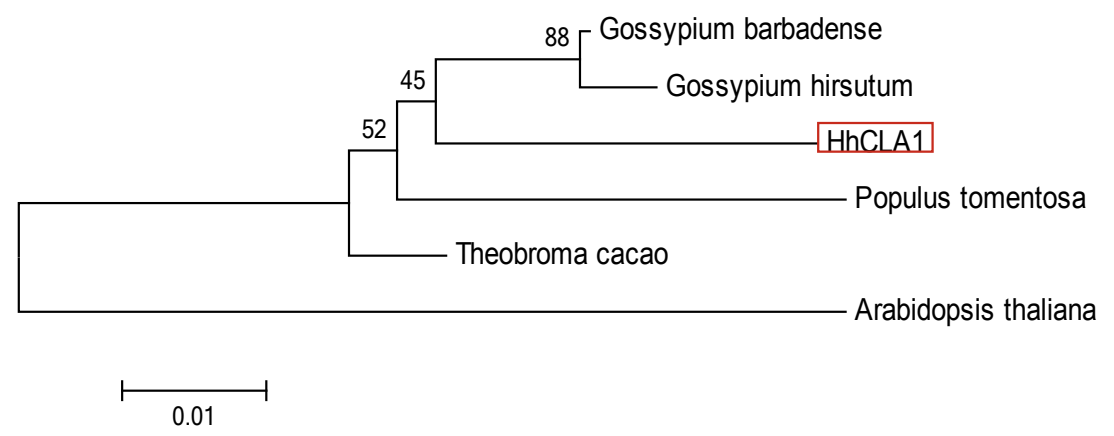

Figure 2 Phylogenetic analysis of the protein of HhCLA1. Phylogenetic analysis of HhCLA1 proteins in different species.

Full-size DOI: 10.7717/peerj.7505/fig-2

\section{RESULTS}

\section{Characterization of the HhCLA1 gene in $H$. hamabo}

The amino acid sequence alignment indicated that the HhCLA1 protein showed high homology to known CLA1 proteins from G. barbadense, G. hirsutum and other species (Fig. 1 and Table S1). The phylogenetic analysis showed that HhCLA1 clustered with G. barbadense and G. hirsutum in a clade (Fig. 2). 


\begin{tabular}{|c|c|c|}
\hline Treatment & Number of plants assayed & Silencing efficiency ${ }^{*}$ \\
\hline pTRV2-HhCLA1 & 52 & $45 / 52(87 \%)$ \\
\hline Mock & 8 & $0 / 8(0 \%)$ \\
\hline Control & 8 & $0 / 8(0 \%)$ \\
\hline
\end{tabular}

Notes.

${ }^{*}$ Silencing efficiency indicates the number of plants showing silencing phenotypes/number of plants treated by TRV-VIGS system.

\section{Silencing efficiency of the HhCLA1 gene in $H$. hamabo using the VIGS system}

In total, fifty-two H. hamabo plants were inoculated with A.tumefaciens 'GV3101' harboring pTRV2-HhCLA1. Two weeks after agroinfiltration, white streaks began to appear in the emerging leaves of partially agroinoculated plants. At three weeks post infiltration, $87 \%$ of the $H$. hamabo plants showed white-streak leaf symptoms similar to the photobleached phenotype (Table 2; Fig. 3A and Fig. S2). At three weeks after agroinfiltration, plants inoculated with pTRV1 and pTRV2 (Mock) showed no obvious differences in leaf morphology compared with the control (Figs. 3B, 3C and Fig. S2). The leaves in Fig. 3D are from plants infiltrated with pTRV2-HhCLA1 (CLA1), empty vector infiltrated plant (Mock) and the control plant (CK) separately. Leaf phenotypic characteristics suggested that the HhCLA1 gene expression might be suppressed in plants infiltrated with pTRV2-HhCLA1 compared with mock and CK plants.

\section{q-PCR analysis of the knockdown levels of HhCLA1}

The efficiency of gene silencing was analyzed by monitoring expression levels of HhCLA1 in plants showing white-streak leaf symptoms. Results showed that HhCLA1 gene expression levels were unchanged in mock-injected plants, while the HhCLA1 expression levels were $62.6 \%-76.4 \%$ lower in the pTRV2-HhCLA1 agroinfiltrated plants than in the noninfiltrated plants (control) (Fig. 4 and Table S2 ). The phenotypic characteristics were consistent with the expression characteristics of HhCLA1. This clearly indicates that the expression of HhCLA1 was significantly down-regulated through TRV-VIGS in H. hamabo, and TRV-VIGS led to an albino phenotype on leaves.

\section{DISCUSSION}

In this study, we demonstrated for the first time that TRV-VIGS can effectively downregulate endogenous gene expression levels in the salt-tolerant species H. hamabo. The genetic transformation of this species is currently laborious, time-consuming and technically challenging. To resolve these problems, effective and low-cost techniques need to be developed to enable the rapid validation of gene functions. In future studies, stress-responsive genes isolated in H. hamabo could be silenced in loss-of-function screens using the TRV-VIGS system.

The CLA1 gene is involved in chloroplast development and is a useful marker in the TRV-VIGS system (Mustafa et al., 2016). In this research, multiple sequence alignments 


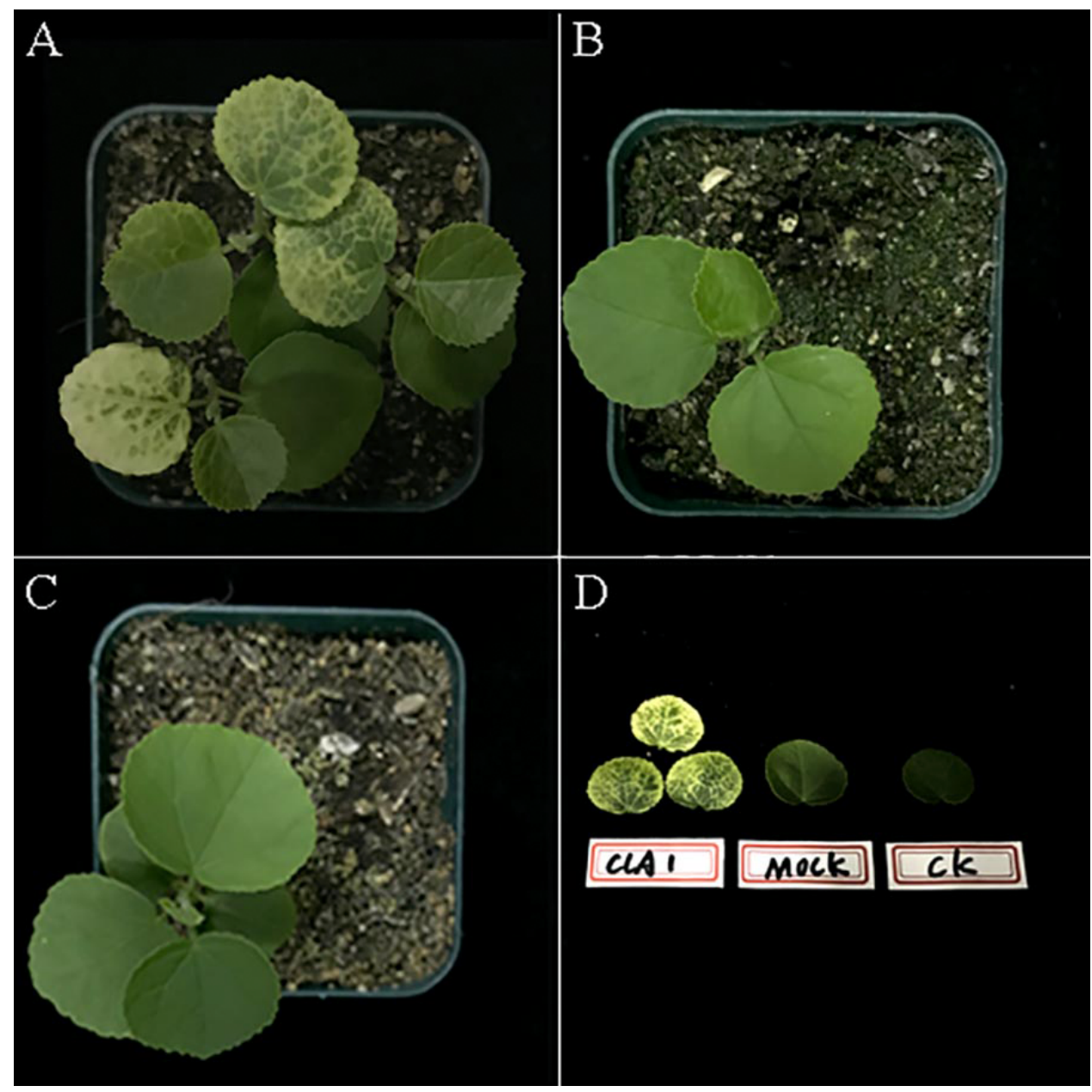

Figure 3 TRV-induced HhCLA1 silencing in H. hamabo. (A) Newly formed leaves of $H$. hamabo plants infiltrated with pTRV2-HhCLA1 (CLA1) showing white-streaked leaf symptoms after three weeks. (B) Empty vector infiltrated plants (Mock) with the normal phenotype. (C) Control plants (CK). (D) The leaf phenotypes of the treatments. The three leaves on the left in Fig. 3D are from plants infiltrated with pTRV2-HhCLA1 (CLA1), the leaf in the middle is from an empty vector infiltrated plant (Mock) and the right one is from a control plant $(\mathrm{CK})$.

Full-size DOI: 10.7717/peerj.7505/fig-3

indicated that HhCLA1 was similar to CLA1 proteins of other species. Additionally, the phylogenetic analysis indicated that HhCLA1 was highly similar to CLA1 proteins in Malvaceae, including G. barbadense and G. hirsutum.

The most cost-efficient and effective method of inoculating plants with virus-based vectors is agroinfection (Grimsley et al., 1986), but its efficiency varies among plants (Zhang et al., 2016). In turf grass, the silencing efficiency of the RTBV-VIGS system in Cynodon dactylon was such that $65.8 \%-72.5 \%$ of the agroinfected plants developed symptoms typical for phytoene desaturase gene silencing, while the silencing efficiency in Zoysia japonica was much lower, with only $52.7 \%-55 \%$ of agroinfected plants developing the phenotype (Zhang et al., 2016). The ability of the TRV vector to directly infect woody plant species has been tested, and TRV-mediated VIGS was effective in Vernicia fordii, weak 


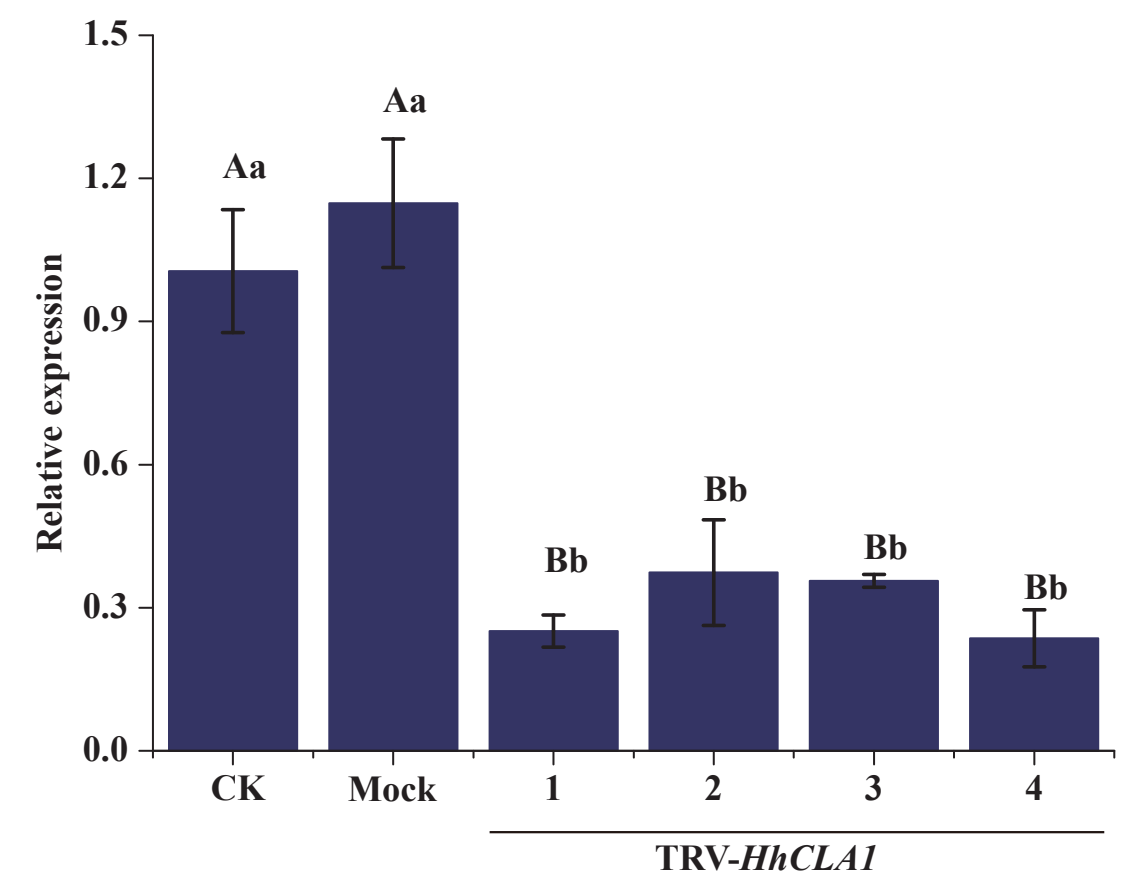

Figure 4 Relative expression levels of HhCLA1 transcripts in control (CK), empty vector-infected (Mock) and pTRV-HhCLA1-infected plants (pTRV2-HhCLA1). Error bars represent standard errors, and any two samples with a common capital letter are not significantly different at the $P<0.01$ level, as with a same small letter are not significantly different at the $P<0.05$ level.

Full-size DOI: 10.7717 /peerj.7505/fig-4

in Populus tomentosa Carr., and ineffective in Camellia oleifera (Jiang et al., 2014). In this study, the silencing efficiency of the TRV-VIGS system in H. hamabo was high, with $87 \%$ of agroinfected plants developing a white-streak leaf phenotype. The HhCLA1 mRNA level was also down-regulated by TRV-VIGS in H. hamabo.

\section{CONCLUSIONS}

In conclusion, we demonstrated that TRV-mediated VIGS can effectively silence genes in H. hamabo, which adds to the increasing list of wood species for which VIGS-mediated studies can be used. The loss-of-function assay using TRV-mediated VIGS developed in this study provides an alternative tool for functional genes studies of H. hamabo.

\section{ACKNOWLEDGEMENTS}

We thank International Science Editing for editing this manuscript.

\section{ADDITIONAL INFORMATION AND DECLARATIONS}

\section{Funding}

The study was supported by Six Talent Peaks Project of Jiangsu Province (NY-042), Jiangsu Province Three New Forestry Projects (LYSX[2016]53) and the 333 Talents Project of 
Jiangsu Province (BRA2017498). The funders had no role in study design, data collection and analysis, decision to publish, or preparation of the manuscript.

\section{Grant Disclosures}

The following grant information was disclosed by the authors:

Six Talent Peaks Project of Jiangsu Province: NY-042.

Jiangsu Province Three New Forestry Projects: LYSX[2016]53.

333 Talents Project of Jiangsu Province: BRA2017498.

\section{Competing Interests}

The authors declare there are no competing interests.

\section{Author Contributions}

- Zhiquan Wang conceived and designed the experiments, performed the experiments, analyzed the data, contributed reagents/materials/analysis tools, prepared figures and/or tables, authored or reviewed drafts of the paper, approved the final draft.

- Xiaoyang Xu conceived and designed the experiments, performed the experiments, analyzed the data, contributed reagents/materials/analysis tools, authored or reviewed drafts of the paper.

- Longjie Ni and Jinbo Guo performed the experiments.

- Chunsun Gu conceived and designed the experiments, performed the experiments, contributed reagents/materials/analysis tools, authored or reviewed drafts of the paper, approved the final draft.

\section{Data Availability}

The following information was supplied regarding data availability:

The HhCLA1 sequence described here is available at GenBank, accession no. MK229167.

\section{Supplemental Information}

Supplemental information for this article can be found online at http://dx.doi.org/10.7717/ peerj.7505\#supplemental-information.

\section{REFERENCES}

Baulcombe D. 1999. Viruses and gene silencing in plants. In: 100 Years of Virology. Archives of Virology. Supplementa, vol. 15. Vienna: Springer, 189-201 DOI 10.1007/978-3-7091-6425-9_14.

Baulcombe D. 2004. RNA silencing in plants. Nature 431(7006):356-363 DOI 10.1038/nature02874.

Becker A, Lange M. 2010. VIGS-genomics goes functional. Trends in Plant Science 15:1-4 DOI 10.1016/j.tplants.2009.09.002.

Burch-Smith TM, Anderson JC, Martin GB, Dinesh-Kumar SP. 2004. Applications and advantages of virus-induced gene silencing for gene function studies in plants. Plant Journal 39(5):734-746 DOI 10.1111/j.1365-313X.2004.02158.x. 
Burch-Smith TM, Schiff M, Liu Y, Dinesh-Kumar SP. 2006. Efficient virus-induced gene silencing in Arabidopsis. Plant Physiology 142:21-27 DOI 10.1104/pp.106.084624.

Fowler E. 2017. Assessment and characterization of microbial communities in salt affected soils on Galveston Island. MS Dissertation, Stephen F Austin State University. Available at https://scholarworks.sfasu.edu/etds/76/.

Fuchs U, Damm-Welk C, Borkhardt A. 2004. Silencing of disease-related genes by small interfering RNAs. Current Molecular Medicine 4:507-517 DOI 10.2174/1566524043360492.

Gao X, Britt Jr RC, Shan L, He P. 2011. Agrobacterium-mediated virus-induced gene silencing assay in cotton. Journal of Visualized Experiments 54:e2938.

Ge X, Wu J, Zhang C, Wang Q, Hou Y, Yang Z, Yang Z, Xu Z, Wang Y, Lu L, Zhang $X$, Hua J, Li F. 2016. Prediction of VIGS efficiency by the Sfold program and its reliability analysis in Gossypium hirsutum. Science Bulletin 61(7):543-551 DOI 10.1007/s11434-016-1032-z.

Grimsley N, Hohn B, Hohn T, Walden R. 1986. Agroinfection, an alternative route for viral infection of plants by using the Ti plasmid. Proceedings of the National Academy of Sciences of the United States of America 83:3282-3286 DOI 10.1073/pnas.83.10.3282.

Gu C, Liu L, Song A, Liu Z, Zhang Y, Huang S. 2018. Iris lactea var. chinensis (Fisch.) cysteine-rich gene $l l C D T 1$ enhances cadmium tolerance in yeast cells and Arabidopsis thaliana. Ecotoxicology and Environmental Safety 157:67-72 DOI 10.1016/j.ecoenv.2018.03.059.

Hayward A, Padmanabhan M, Dinesh-Kumar S. 2011. Virus-induced gene silencing in Nicotiana benthamiana and other plant species. Methods in Molecular Biology 678:55-63 DOI 10.1007/978-1-60761-682-5_5.

Höfgen R, Willmitzer L. 1988. Storage of competent cells for Agrobacterium transformation. Nucleic Acids Research 16(20):9877 DOI 10.1093/nar/16.20.9877.

Jiang Y, Ye S, Wang L, Duan Y, Lu W, Liu H, Fan D, Zhang F, Luo K. 2014. Heterologous gene silencing induced by tobacco rattle virus (TRV) is efficient for pursuing functional genomics studies in woody plants. Plant Cell Tissue \& Organ Culture 116:163-174 DOI 10.1007/s11240-013-0393-0.

Krishnan A, Mahadevan C, Mani T, Sakuntala M. 2015. Virus-induced gene silencing (VIGS) for elucidation of pathogen defense role of serine/threonine protein kinase in the non-model plant Piper colubrinum Link. Plant Cell Tissue \& Organ Culture 122:269-283 DOI 10.1007/s11240-015-0764-9.

Kumagai M, Donson J, Della-Cioppa G, Harvey D, Hanley K, Grill L. 1995. Cytoplasmic inhibition of carotenoid biosynthesis with virus-derived RNA. Proceedings of the National Academy of Sciences of the United States of America 92:1679-1683 DOI 10.1073/pnas.92.5.1679.

Li J, Liao J, Guan M, Wang E, Zhang J. 2012. Salt tolerance of Hibiscus hamabo seedlings: a candidate halophyte for reclamation areas. Acta Physiologiae Plantarum 34:1747-1755 DOI 10.1007/s11738-012-0971-5. 
Liao YL, Xu F, Zang WW, Cheng SY, Shen YB, Chang J. 2016. Cloning, characterization and expression analysis of GbWRKY11, a novel transcription factor gene in Ginkgo biloba. International Journal of Agriculture and Biology 18(1):117-124.

Liu C, Wang G, Wang H, Xia T, Zhang S, Wang Q, Fang Y. 2015. Phylogenetic relationships in the genus Rosa revisited based on rpl16, trnL-F, and atpB-rbcL sequences. HortScience 50(11):1618-1624 DOI 10.21273/HORTSCI.50.11.1618.

Liu Y, Schiff M, Dinesh-Kumar S. 2002. Virus-induced gene silencing in tomato. The Plant Journal 31:777-786 DOI 10.1046/j.1365-313X.2002.01394.x.

Lu R, Martin-Hernandez AM, Peart JR, Malcuit I, Baulcombe DC. 2003. Virus-induced gene silencing in plants. Methods 30(4):296-303

DOI 10.1016/S1046-2023(03)00037-9.

Manhães AMEDA, De Oliveira MV, Shan L. 2015. Establishment of an efficient virus-induced gene silencing (VIGS) assay in Arabidopsis by agrobacteriummediated rubbing infection. Methods in Molecular Biology 1287:235-241

DOI 10.1007/978-1-4939-2453-0_17.

Mustafa R, Shafiq M, Mansoor S, Briddon RW, Scheffler BE, Scheffler J, Amin I. 2016. Virus-induced gene silencing in cultivated cotton (Gossypium spp.) using tobacco rattle virus. Molecular Biotechnology 58:65-72 DOI 10.1007/s12033-015-9904-z.

Nakanishi H. 1979. Distribution and ecology of a semi-mangrove plant, Hibiscus hamabo SIEB. et ZUCC. and its community. Acta Phytotaxonomica Et Geobotanica 30:169-179.

Orzaez D, Medina A, Torre S, Fernández-Moreno JP, Rambla JL, Fernández-del Carmen A, Butelli E, Martin C, Granell A. 2009. A visual reporter system for virusinduced gene silencing in tomato fruit based on anthocyanin accumulation. Plant Physiology 150:1122-1134 DOI 10.1104/pp.109.139006.

Purkayastha A, Dasgupta I. 2009. Virus-induced gene silencing: a versatile tool for discovery of gene functions in plants. Plant Physiology and Biochemistry 47:967-976 DOI 10.1016/j.plaphy.2009.09.001.

Scofield SR, Huang L, Brandt AS, Gill BS. 2005. Development of a virus-induced gene-silencing system for hexaploid wheat and its use in functional analysis of the Lr21-mediated leaf rust resistance pathway. Plant Physiology 138:2165-2173 DOI 10.1104/pp.105.061861.

Waterhouse PM, Wang MB, Lough T. 2001. Gene silencing as an adaptive defence against viruses. Nature 411:834-842 DOI 10.1038/35081168.

Yang H, Du GJ, Wang KH. 2008. Study on the Physiological Characteristics of Hibiscus hamabo under Stress. Journal of Zhejiang Forestry Science and Technology 3:43-47.

Zhang B, Shi J, Chen J, Li D, Li J, Guo H, Zong J, Wang Y, Guo A, Liu J. 2016. Efficient virus-induced gene silencing in Cynodon dactylon and Zoysia japonica using rice tungro bacilliform virus vectors. Scientia Horticulturae 207:97-103 DOI 10.1016/j.scienta.2016.05.030. 